\title{
Female Genital Tract Secretions Inhibit Herpes Simplex Virus Infection: Correlation with Soluble Mucosal Immune Mediators and Impact of Hormonal Contraception
}

\author{
Gail F. Shust, M.D1, Sylvia Cho, B.S. ${ }^{1}$, Mimi Kim, PhD², Rebecca P. Madan, M.D. ${ }^{1}$, \\ Esmeralda M. Guzman, M.S. ${ }^{1}$, Margaret Pollack, M.D. ${ }^{1}$, Julia Epstein, B.A. ${ }^{4}$, Hillel W.

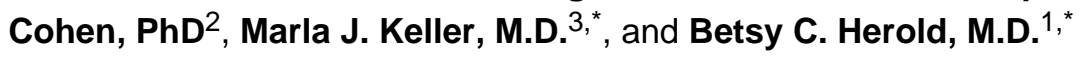 \\ ${ }^{1}$ Albert Einstein College of Medicine, Department of Pediatrics, Bronx, NY \\ ${ }^{2}$ Albert Einstein College of Medicine, Department of Epidemiology \& Population Health, Bronx, \\ NY \\ ${ }^{3}$ Albert Einstein College of Medicine, Department of Medicine, Bronx, NY \\ ${ }^{4}$ Mount Sinai School of Medicine, Department of Medicine, New York, NY
}

\begin{abstract}
Problem-Female genital tract secretions inhibit HSV infection, however, the intra- and intersubject variability, contribution of specific mediators, and impact of reproductive hormones have not been defined.

Method of Study-Cervicovaginal lavage (CVL) ( $\mathrm{n}=89$ ) obtained from nine cyclers and seven women on hormonal contraception, who completed between three and eight weekly visits, were examined for anti-HSV activity and concentrations of mediators.
\end{abstract}

Results-CVL inhibited HSV infection by a mean of $\sim 57 \%$ during the follicular or luteal phase, but only by $36 \%$ in hormonal contraceptive users. Human neutrophil peptides1-3 (HNP1-3) ( $\mathrm{p}=0.03), \operatorname{IL}-8$ ( $\mathrm{p}=0.003)$, lactoferrin ( $\mathrm{p}=0.005)$, lysozyme $(\mathrm{p}=0.003), \operatorname{IgA}(\mathrm{p}=0.002)$, and $\operatorname{IgG}$ $(\mathrm{p}=0.02)$ correlated with antiviral activity. Intra-subject and inter-subject variability was observed, suggesting that factors other than hormones contribute to innate defense.

Conclusions-Endogenous antimicrobial activity may provide a biomarker of healthy mucosal immunity and may be reduced in the setting of hormonal contraception. However, larger prospective studies are needed.

\section{Keywords}

genital herpes; mucosal immunity; reproductive hormones; microbicides

\footnotetext{
Corresponding Author: Betsy C. Herold, M.D., Albert Einstein College of Medicine. 1300 Morris Park Avenue, Forchheimer 702, Bronx, NY 10467; 718-430-2975 (phone); 718-430-2199 (fax); bherold@ aecom.yu.edu. 


\section{Introduction}

Prevention of sexually transmitted infections (STI) is a global health priority. Data from the US National Health and Nutrition Examination Surveys indicates that $17.7 \%$ of the population is seropositive for HSV-2 and $58 \%$ for HSV-1, which is emerging as a major cause of genital herpes infections ${ }^{1}$. The seroprevalence is higher among females than males (23.1\% vs. $11.2 \%$ ). In developing countries, the rates of HSV-2 reach 90-95\% among HIVinfected persons and female sex workers ${ }^{2}$. The worldwide prevalence of HSV-2 coupled with the epidemiological findings that HSV-2 increases HIV acquisition and transmission highlight the urgent need for novel prevention strategies ${ }^{3}$.

Women are more susceptible to genital HSV than men, suggesting that factors in the female genital tract might impact acquisition ${ }^{4}$. The multilayered squamous epithelium in the vagina and ectocervix provides the first line of defense against STI. Disruption of this barrier enhances STI acquisition, as illustrated by the increased risk of HIV acquisition in the setting of cervical ectopy or following exposure to nonoxynol-9 ${ }^{5,6}$. Vaginal flora, acidic $\mathrm{pH}$, mucus and soluble immune mediators also play important roles in host defense. Specifically, we previously observed that genital tract secretions obtained by cervicovaginal lavage (CVL) from healthy women have potent anti-HSV activity and inhibit infection in vitro by as much as $90 \%$, although the inter- and intra-subject variability and impact of hormonal contraception on this defense was not examined ${ }^{7,8}$.

The biological significance of this innate defense was supported by the observation that human CVL protected mice from genital HSV-2 ${ }^{8}$. We speculate that this endogenous antiviral activity may protect against HSV, particularly disease extending beyond the vaginal introitus. Exposure to HSV is common as demonstrated by a high frequency of subclinical HSV shedding among HSV-2 seropositive subjects who collected anogenital swabs 4 times/day for 60 days ${ }^{9}$. HSV-2 was detected by PCR on $19 \%$ of days with a median duration of 13 hours. However, a study among HSV-2 discordant couples found that over an 8 -month period, the incidence of HSV-2 seroconversion was only $3.6 \%{ }^{10}$. Moreover, most primary genital herpes lesions are evident in the vulvar and/or introital epithelium. Cervicitis is observed less commonly and virus can be isolated from the cervix in only $10 \%$ to $15 \%$ of patients during vulvar recurrences ${ }^{11}$.

We hypothesize that the endogenous anti-HSV activity reflects the concerted activity of multiple soluble mucosal immune mediators and may be modulated by reproductive hormones. The effects of estrogens are complex and include direct effects on intracellular estrogen receptors, which down-regulate gene transcription, or indirect interactions with other transcription factors ${ }^{12}$. The notion that estrogen influences soluble immune mediators is supported by studies indicating that immunoglobulins, human $\beta$ defensins (HBD) and secretory leukocyte protease inhibitor (SLPI) are lowest at mid-cycle when ovulation occurs and when estradiol levels are elevated $7,13,14$. Thus, the current study was designed to examine the intra- and inter-subject variability in endogenous anti-HSV activity and levels of mediators of mucosal defenses by obtaining weekly CVL from cycling women and HC users. 


\section{Materials and Methods}

\section{Subjects}

Following Institutional Review Board approval by the Mount Sinai School of Medicine and Albert Einstein College of Medicine, informed consent was obtained from healthy women, 18-35 years of age. Enrollment criteria included a normal menstrual history, no change in contraceptive use in the three months prior to screening and low risk for STI (defined as sexually abstinent or in a stable, mutually monogamous relationship with a partner not known to be HIV-infected). Hormonal contraception included women using oral contraceptive pills or intravaginal ring. Exclusions included: pregnancy; menopause; an STI, urinary tract infection (UTI) or abnormal Pap test at screening; inter-menstrual bleeding; gynecological surgery or STI treatment in the three months prior to screening; Candida, bacterial vaginosis (BV), or a UTI in the month prior to screening; use of vaginal products or sex 48 hours prior to screening; or chronic illness.

At screening, which occurred 2-5 days after cessation of menses, subjects had a urinalysis and culture, pregnancy test, Pap test, and gynecological examination for detection of BV, Trichomonas vaginalis, Candida species and semen. Neisseria gonorrhoeae and Chlamydia trachomatis infection were determined by DNA probe. Blood was drawn for HIV-1 (ELISA), syphilis (RPR), type-specific HSV antibody testing (Focus Immunoblot, Cypress, CA), estradiol and progesterone. Participants were instructed to abstain from sex for 48 hours prior to each visit.

\section{CVL}

CVL was collected weekly for a total of 8 visits by washing the cervical os and posterior vaginal wall with $10 \mathrm{~mL}$ of phosphate buffer saline (PBS, pH 7.0). Samples were transported on ice and centrifuged at 1000g for 20 minutes. Antibiotics (final concentrations: penicillin, $500 \mathrm{U} / \mathrm{mL}$; streptomycin, $50 \mathrm{mg} / \mathrm{mL}$; amphotericin, $0.5 \mathrm{mg} / \mathrm{mL}$ ) and protease inhibitor (PI) cocktail (Roche Diagnostics, Mannheim, Germany) were added to the supernatants and aliquots were stored at $-80^{\circ} \mathrm{C}$.

\section{Plaque assays}

CaSki (human cervical epithelial) cells were plated in 24-well dishes and infected with serial dilutions of HSV-2(G) (0.01 to $10 \mathrm{PFU} /$ cell) in the presence of each CVL or a matched control buffer (PBS, pH 7.0, 1.5mg/ml bovine serum albumin and antibiotics and PI as added to CVL samples). After 1-h incubation at $37^{\circ} \mathrm{C}$, the cells were washed and overlaid with fresh medium. Plaques were counted after 48 hours by immunoassay ${ }^{15}$. Wells with plaques ranging from 20 to 150 were used to calculate the viral titer. All samples were tested in duplicate in two independent experiments.

\section{Measurement of immune mediators}

The concentration of the following were measured in each CVL sample: total protein (BCA Protein Kit, Rockford, IL); IL-1a, IL-1 $\beta$, IL-6, IL-8, IFN- $\gamma$, IFNa2 and RANTES (multiplex proteome array with beads from Chemicon International (Billerica, MA), measured using Luminex ${ }^{100}$ (Austin, TX) and analyzed using StarStation (Applied Cytometry Systems, 
Sacramento, CA)); SLPI and human IL-1ra (R \& D Systems, Minneapolis, MN), lactoferrin (Calbiochem, San Diego, CA), human neutrophil peptides 1-3 (HNP1-3) (HyCult Biotechnology, Uden, The Netherlands), HBD-3 (Alpha Diagnostics, San Antonio, TX), IgG and IgA (Cygnus Technologies, Southport, NC) lysozyme (Alpco Diagnostics, Salem, $\mathrm{NH})$; and HBD-2 ${ }^{16}$, each by the indicated ELISA.

\section{Statistical analysis}

Demographic characteristics were compared between the cyclers and women on HC using the Fisher's exact test for categorical variables and Mann Whitney test for continuous variables. Between group differences in antiviral activity and immune mediators were analyzed by fitting mixed effects linear models to account for the correlation among repeated measurements obtained from the same subject. In addition, because the number of repeated measurements varied across subjects, associations between antiviral activity and immune mediators were evaluated by estimating weighted Pearson product-moment correlations to the subject specific averages with weights equal to the number of repeated measurements from each individual ${ }^{17}$. The intra-class correlation coefficient (ICC) estimated from the between and within-subjects variance components of a one-way random effects model was used to quantify the reliability of the different measurements. Two-sided p-values less than 0.05 were considered statistically significant. All analyses were performed with SAS version 9.1 (SAS Institute Inc., Cary, N.C.).

\section{Results}

Twenty-six women were screened and 16 (nine cyclers and seven on HC) completed between three and eight visits and were included in the analysis, 7 of whom completed all 8 visits. Reasons for exclusion included BV ( $\mathrm{n}=3)$, candidiasis $(\mathrm{n}=1)$, and Pap test findings of atypical squamous cells of undetermined significance $(n=4)$ or low grade squamous intraepithelial lesion (LGSIL) ( $\mathrm{n}=3$ ). One participant had both BV and LGSIL. Reasons for early withdrawal included UTI $(n=1), B V(n=1)$, candidiasis $(n=3)$, travel $(n=2)$ and personal reasons $(n=2)$. There were no significant differences between cyclers or women on HC with respect to age $(p=0.68)$, race $(p=0.15)$ or HSV serostatus $(p=0.61)$ (Table 1$)$. The various forms of hormonal contraceptives used are listed in Table 1.

A total of $94 \mathrm{CVL}$ samples were collected; 38 from women on $\mathrm{HC}, 25$ from women determined to be in the follicular phase (based on history and/or an estradiol level of 11-165 $\mathrm{pg} / \mathrm{ml}$ and progesterone level of $0.15-1.4 \mathrm{ng} / \mathrm{ml}), 26$ from women determined to be luteal phase of their cycle (based on history and an estradiol level of 33-196 pg/ml and progesterone level of 3.3-25.6 ng/ml), and 5 whose phase could not be determined and were excluded from further analysis.

\section{Decreased endogenous anti-HSV activity among women on HC}

When the antiviral activity from each sample was analyzed as an independent data point, CVL obtained during the follicular or luteal phase of the menstrual cycle inhibited HSV infection by a mean of $61.6 \%$ and $61.3 \%$, respectively compared to $33.9 \%$ for CVL from women on HC ( $\mathrm{p}$ <.05) (Figure 1). However, because the two groups of women (cycling 
versus HC) contributed different numbers of samples to each of the 3 groups (follicular, luteal and HC) and the repeated samples from the same subjects may be correlated, the mean anti-HSV activity obtained from averaging the subject-specific means of repeat samples from each woman were compared.

CVL from each of the groups inhibited HSV-2 infection by $56.7 \%, 57.5 \%$ and $35.9 \%$, respectively, which again indicates a trend towards decreased endogenous antimicrobial activity among women using $\mathrm{HC}$ although the differences were no longer statistically significant ( $p=0.14$ follicular vs. HC and $\mathrm{p}=0.09$ luteal vs. HC) because of the smaller effective sample size. Notably, there was substantial intra- and inter-subject variability in the anti-HSV activity (ICC: 0.44-0.63) even among women using HC, suggesting that factors other than reproductive hormones contribute to the variance in endogenous anti-HSV activity. The antiviral activity did not correlate with the serum levels of estrogen or progesterone (not shown).

\section{Anti-HSV activity correlates with soluble mucosal immune mediators}

Genital tract epithelial and immune cells produce soluble factors that contribute to mucosal defenses including defensins, SLPI, immunoglobulins, lysozyme and lactoferrin. In addition, cytokines and chemokines play important roles in host defense by recruiting and/or activating immune cells and through direct antiviral activity in the case of interferons (IFNs). Concentrations of mediators were determined in each of the CVL samples (Table 2). The concentration of IgG was greater than IgA, as has been previously observed in the genital tract ${ }^{18}$. The concentrations of HNP1-3 and HBD-3 were lower in the hormonal contraceptive group compared to cyclers, which was significant for HBD-3 ( $\mathrm{p}=0.05)$. In addition, both HNP1-3 and HBD3 were also lower during the follicular compared to the luteal phase ( $\mathrm{p}=0.05$ for both), although the clinical implications of this observation will require larger studies. No other significant differences in the concentration of individual mediators were observed between the three groups or between HSV-seropositive and HSVseronegative women. While the limited number of HSV negative subjects among cyclers precludes meaningful analyses of subgroups defined by HSV status, no statistically significant differences were observed when mediator levels were compared between the HSV-positive and HSV- negative groups for both the follicular and luteal phase (not shown).

We then examined whether the concentration of specific mediators correlated with the antiHSV activity. The anti-HSV activity correlated significantly with the concentrations of HNP1-3 ( $\mathrm{p}=0.03$ ), IL-8 ( $\mathrm{p}=0.003$ ), lactoferrin ( $\mathrm{p}=0.005)$, lysozyme ( $\mathrm{p}=0.003), \operatorname{IgA}$ $(\mathrm{p}=0.003)$, and $\operatorname{IgG}(\mathrm{p}=0.02)$ (Table 2, Figure 2). Notably, the correlation between endogenous anti-HSV activity and $\operatorname{IgA}$ and $\operatorname{IgG}$ levels persisted when only the HSV seronegative participants were included in the analysis, suggesting that the activity is not mediated by HSV specific antibody ( $\mathrm{p}=0.0001$ and $\mathrm{p}=0.002$ ).

\section{Reliability of measurements}

Phase I vaginal microbicide studies have begun to include inflammatory cytokines and chemokines or immune mediators as potential biomarkers of microbicide safety ${ }^{19-25}$. 
However, little is known about the variation in these mediators in the absence of microbicides. To address this gap, the ICCs of the soluble mucosal immune mediators and anti-HSV activity were calculated (Table 3). Several variables including total protein, IL-8, IFN- $\gamma$, and RANTES showed relatively high ICCs in all three groups, whereas lower ICCs were observed for others. For example, the ICC for anti-HSV activity was relatively high (0.63) during the follicular phase, but only 0.44 during the luteal phase and for samples obtained from women on HC. These results suggest that factors other than reproductive hormones contribute to the variability and that repeat measures will be required if measurements of specific mediators or endogenous anti-HSV activity are to be developed as biomarkers of mucosal immunity and microbicide safety.

\section{Discussion}

This pilot prospective study was designed to evaluate the intra- and inter-subject variability in the endogenous anti-HSV activity in CVL, to determine whether the phase of menstrual cycle or use of $\mathrm{HC}$ modified this activity, and to identify mediators that contribute to this innate defense. Despite substantial intra- and inter-subject variability, we observed a trend towards reduced anti-HSV activity in CVL obtained from women using HC compared to women who were cycling. If confirmed by larger studies, these results may provide a biological explanation for the epidemiological link between $\mathrm{HC}$ and an increased risk for HSV acquisition and shedding. For example, a cross-sectional study found that women on combined oral contraceptive pills had an increased risk for HSV-2 acquisition, after adjusting for sexual behaviors (OR, 7.4; 95\% CI, 2.2-24.9) ${ }^{26}$. Additionally, in a longitudinal study of $330 \mathrm{HSV}-2$ seropositive women, the use of $\mathrm{HC}$ was an independent predictor of genital HSV-2 shedding (adjusted OR, 1.8; 95\% CI, 1.1-2.8) ${ }^{27}$.

The overall antiviral activity observed in the current study was less than previously observed, possibly reflecting differences in collection methods. In this study, we collected CVL in PBS, $\mathrm{pH} 7.0$, to simulate the $\mathrm{pH}$ following coitus, the time at which women are most likely to be exposed to pathogens. CVL was previously collected in saline ( $\mathrm{pH} \sim 5.0-5.5)$ and inhibited HSV infection by a mean of $87 \%{ }^{8}$. Both studies may underestimate the full extent of antiviral activity within the genital tract because of the impact of the diluent. The buffering effects of PBS may interfere with the portion of antimicrobial activity attributable to an acidic $\mathrm{pH}$ environment. For example, SLPI, which inhibits HIV by binding to annexin and interfering with HIV binding to macrophages, fails to interact with annexin under basic $\mathrm{pH}$ conditions ${ }^{28}$. In addition, the high salt concentration of saline may interfere with the activity of defensins 29,30 . Greater activity may be observed with fluid collected with swabs or from cervically placed cups, which would limit the dilutional effects of lavage. However, a major advantage of CVL is that the quantity obtained allows for repeated measurements.

Consistent with our prior study, which focused only on HNP1-3 and SLPI, the anti-HSV activity of CVL correlated with the concentration of HNP1-3, but not SLPI ${ }^{8}$. HNP1-3 inhibits HSV infection at concentrations as low as $1-5 \mu \mathrm{g} / \mathrm{ml}$ primarily by blocking viral binding and entry and our prior work demonstrated that CVL acts by a similar mechanism ${ }^{8,16}$. The mean concentration of HNP1-3 detected in the CVL samples was 
$1.02 \mu \mathrm{g} / \mathrm{ml}$, but presumably the local concentrations are higher supporting a role for HNP1-3 in mucosal defense.

In the current study we identified several additional mediators that correlated with the endogenous antiviral activity including IL-8, lysozyme, lactoferrin, IgA and IgG. It remains to be determined to what extent each of these factors contributes directly to the antiviral activity. The association of anti-HSV activity with higher levels of IL-8 may reflect its role as a chemokine, rather than any direct antiviral activity. Consistent with this, we found that IL-8 concentrations positively correlated with HNP1-3 (data not shown). Thus, IL-8 may recruit white blood cells into the genital tract, which then serve as a source for HNP1-3.

Lysozyme is a family of enzymes with bacteriolytic properties found in relatively high concentrations in seminal plasma, saliva and tears ${ }^{31}$. The concentrations detected in the current study are relatively low, however prior studies have detected higher concentrations in cervical mucus plugs ( $\sim 1 \mathrm{mg} / \mathrm{g}$ of plug) ${ }^{32}$. The anti-HSV activity of lysozyme has not been evaluated, but in ongoing work, we found that the addition of lysozyme-specific mAbs to CVL reduced its anti-HSV activity, supporting a potential role for lysozyme in host defense. Lactoferrin, an antibacterial glycoprotein produced by epithelial cells and neutrophils, has been demonstrated to inhibit HSV in vitro and binds to heparan sulfate and competitively blocks HSV binding and cell-to-cell spread ${ }^{33-35}$.

The concentration of $\operatorname{IgA}$ and $\operatorname{IgG}$ in the CVL samples also correlated with the anti-HSV activity. This does not appear to reflect the impact of HSV-specific mucosal antibodies as the correlation persisted when only the HSV seronegative participants were included in the analysis. Insufficient material was available to measure HSV specific immunoglobulins in CVL, but should be incorporated into future studies. Notably, genital tract IgA has been suggested to play a role in highly HIV-exposed persistently seronegative individuals 36,37 . HIV-neutralizing IgA in cervicovaginal secretions was associated with reduced risks for HIV acquisition, although repeat sampling was not performed and the intra-subject variability in the HIV-neutralizing $\operatorname{IgA}$ was not determined ${ }^{38}$.

While a few mediators such as IL-8 and lysozyme are associated with a relatively high reliability coefficient, others show substantial intra-subject variability, underscoring the need for repeat sampling. Some factors were more reliable in CVL obtained during the follicular phase (e.g. antiviral activity), whereas others were more reliable during the luteal phase (e.g. HBD-2) and some showed little reliability during either phase of the menstrual cycle nor among women on HC (e.g. SLPI). The variability observed within the same stage of the cycle or in the setting of $\mathrm{HC}$ suggests that factors other than reproductive hormones contribute to changes in soluble mucosal defense. For example, we did not examine vaginal flora or immune cells, which might also impact mucosal immunity. In addition, the biological activity of defensins may be modified by matrix metalloproteinases or kallikreins, which process antimicrobial peptides and may be regulated by reproductive hormones 39,40 . It should be noted that the intra- and inter-assay variability itself is low and thus unlikely to have contributed substantially to the observed intra-subject variability. These findings highlight the difficulty in advancing individual mediators or endogenous activity as biomarkers of microbicide safety unless repeat samples are obtained or, in the case of 
variables that show reliability during one phase of the cycle, samples are always obtained during that phase.

Results of this study support the need for larger prospective studies with more frequent sampling to further define genital tract soluble mucosal immunity in different populations. Possibly, HSV-exposed but uninfected women have greater endogenous anti-HSV activity and higher levels of protective mediators compared to exposed women who become infected. Soluble mucosal immunity may also influence the extent and duration of cervical and vaginal HSV shedding following reactivation. If specific antimicrobial proteins do contribute to protection, these could be exploited as part of a prevention strategy either by inducing their expression or providing the protective proteins exogenously.

\section{Acknowledgments}

We thank Julie Petrie for assisting with subject recruitment. This work was supported by T32AI070117, M01RR00071, UL1RR025750 and AI065309. Its contents are solely the responsibility of the authors and do not necessarily represent the official views of NIH.

\section{References}

1. Xu F, Sternberg MR, Kottiri BJ, McQuillan GM, Lee FK, Nahmias AJ, Berman SM, Markowitz LE. Trends in herpes simplex virus type 1 and type 2 seroprevalence in the United States. JAMA. 2006; 296:964-973. [PubMed: 16926356]

2. Nagot N, Ouedraogo A, Konate I, Weiss HA, Foulongne V, Defer MC, Sanon A, Becquart P, Segondy M, Sawadogo A, Van de Perre P, Mayaud P. Roles of Clinical and Subclinical Reactivated Herpes Simplex Virus Type 2 Infection and Human Immunodeficiency Virus Type 1 (HIV-1)Induced Immunosuppression on Genital and Plasma HIV-1 Levels. J Infect Dis. 2008; 198:241249. [PubMed: 18593294]

3. Freeman EE, Weiss HA, Glynn JR, Cross PL, Whitworth JA, Hayes RJ. Herpes simplex virus 2 infection increases HIV acquisition in men and women: systematic review and meta-analysis of longitudinal studies. Aids. 2006; 20:73-83. [PubMed: 16327322]

4. Mertz GJ, Benedetti J, Ashley R, Selke SA, Corey L. Risk factors for the sexual transmission of genital herpes. Ann Intern Med. 1992; 116:197-202. [PubMed: 1309413]

5. Moss GB, Clemetson D, D’Costa L, Plummer FA, Ndinya-Achola JO, Reilly M, Holmes KK, Piot P, Maitha GM, Hillier SL, et al. Association of cervical ectopy with heterosexual transmission of human immunodeficiency virus: results of a study of couples in Nairobi, Kenya. J Infect Dis. 1991; 164:588-591. [PubMed: 1869844]

6. Van Damme L, Ramjee G, Alary M, Vuylsteke B, Chandeying V, Rees H, Sirivongrangson P, Mukenge-Tshibaka L, Ettiegne-Traore V, Uaheowitchai C, Karim SS, Masse B, Perriens J, Laga M. Effectiveness of COL-1492, a nonoxynol-9 vaginal gel, on HIV-1 transmission in female sex workers: a randomised controlled trial. Lancet. 2002; 360:971-977. [PubMed: 12383665]

7. Keller MJ, Guzman E, Hazrati E, Kasowitz A, Cheshenko N, Wallenstein S, Cole AL, Cole AM, Profy AT, Wira CR, Hogarty K, Herold BC. PRO 2000 elicits a decline in genital tract immune mediators without compromising intrinsic antimicrobial activity. Aids. 2007; 21:467-476. [PubMed: 17301565]

8. John M, Keller MJ, Fam EH, Cheshenko N, Hogarty K, Kasowitz A, Wallenstein S, Carlucci MJ, Tuyama AC, Lu W, Klotman ME, Lehrer RI, Herold BC. Cervicovaginal secretions contribute to innate resistance to herpes simplex virus infection. J Infect Dis. 2005; 192:1731-1740. [PubMed: 16235171]

9. Mark KE, Wald A, Magaret AS, Selke S, Olin L, Huang ML, Corey L. Rapidly cleared episodes of herpes simplex virus reactivation in immunocompetent adults. J Infect Dis. 2008; 198:1141-1149. [PubMed: 18783315] 
10. Corey L, Wald A, Patel R, Sacks SL, Tyring SK, Warren T, Douglas JM Jr, Paavonen J, Morrow RA, Beutner KR, Stratchounsky LS, Mertz G, Keene ON, Watson HA, Tait D, Vargas-Cortes M. Once-daily valacyclovir to reduce the risk of transmission of genital herpes. N Engl J Med. 2004; 350:11-20. [PubMed: 14702423]

11. Stamm WE, Handsfield HH, Rompalo AM, Ashley RL, Roberts PL, Corey L. The association between genital ulcer disease and acquisition of HIV infection in homosexual men. Jama. 1988; 260:1429-1433. [PubMed: 3404600]

12. Paech K, Webb P, Kuiper GG, Nilsson S, Gustafsson J, Kushner PJ, Scanlan TS. Differential ligand activation of estrogen receptors ERalpha and ERbeta at AP1 sites. Science. 1997; 277:1508-1510. [PubMed: 9278514]

13. King AE, Fleming DC, Critchley HO, Kelly RW. Differential expression of the natural antimicrobials, beta-defensins 3 and 4, in human endometrium. J Reprod Immunol. 2003; 59:1-16. [PubMed: 12892899]

14. King AE, Critchley HO, Kelly RW. Innate immune defences in the human endometrium. Reprod Biol Endocrinol. 2003; 1:116. [PubMed: 14641912]

15. Herold BC, Siston A, Bremer J, Kirkpatrick R, Wilbanks G, Fugedi P, Peto C, Cooper M. Sulfated carbohydrate compounds prevent microbial adherence by sexually transmitted disease pathogens. Antimicrob Agents Chemother. 1997; 41:2776-2780. [PubMed: 9420059]

16. Hazrati E, Galen B, Lu W, Wang W, Ouyang Y, Keller MJ, Lehrer RI, Herold BC. Human alphaand beta-defensins block multiple steps in herpes simplex virus infection. J Immunol. 2006; 177:8658-8666. [PubMed: 17142766]

17. Bland JM, Altman DG. Calculating correlation coefficients with repeated observations: Part 2-Correlation between subjects. Bmj. 1995; 310:633. [PubMed: 7703752]

18. Usala SJ, Usala FO, Haciski R, Holt JA, Schumacher GF. IgG and IgA content of vaginal fluid during the menstrual cycle. J Reprod Med. 1989; 34:292-294. [PubMed: 2715991]

19. Schwartz JL, Mauck C, Lai JJ, Creinin MD, Brache V, Ballagh SA, Weiner DH, Hillier SL, Fichorova RN, Callahan M. Fourteen-day safety and acceptability study of $6 \%$ cellulose sulfate gel: a randomized double-blind Phase I safety study. Contraception. 2006; 74:133-140. [PubMed: 16860051]

20. Mauck CK, Ballagh SA, Creinin MD, Weiner DH, Doncel GF, Fichorova RN, Schwartz JL, Chandra N, Callahan MM. Six-day randomized safety trial of intravaginal lime juice. J Acquir Immune Defic Syndr. 2008; 49:243-250. [PubMed: 18845958]

21. Bollen LJ, Blanchard K, Kilmarx PH, Chaikummao S, Connolly C, Wasinrapee P, Srivirojana N, Achalapong J, Tappero JW, McNicholl JM. No increase in cervicovaginal proinflammatory cytokines after Carraguard use in a placebo-controlled randomized clinical trial. J Acquir Immune Defic Syndr. 2008; 47:253-257. [PubMed: 18025996]

22. Keller MJ, Zerhouni-Layachi B, Cheshenko N, John M, Hogarty K, Kasowitz A, Goldberg CL, Wallenstein S, Profy AT, Klotman ME, Herold BC. PRO 2000 gel inhibits HIV and herpes simplex virus infection following vaginal application: a double-blind placebo-controlled trial. J Infect Dis. 2006; 193:27-35. [PubMed: 16323128]

23. Fichorova RN. Guiding the vaginal microbicide trials with biomarkers of inflammation. J Acquir Immune Defic Syndr. 2004; 37 (Suppl 3):S184-193. [PubMed: 16419271]

24. Fichorova RN, Bajpai M, Chandra N, Hsiu JG, Spangler M, Ratnam V, Doncel GF. Interleukin (IL)-1, IL-6, and IL-8 predict mucosal toxicity of vaginal microbicidal contraceptives. Biol Reprod. 2004; 71:761-769. [PubMed: 15128598]

25. Trifonova RT, Bajpai M, Pasicznyk JM, Chandra N, Doncel GF, Fichorova RN. Biomarkers of leukocyte traffic and activation in the vaginal mucosa. Biomarkers. 2007; 12:608-622. [PubMed: 17852080]

26. Smith JS, Herrero R, Munoz N, Eluf-Neto J, Ngelangel C, Bosch FX, Ashley RL. Prevalence and risk factors for herpes simplex virus type 2 infection among middle-age women in Brazil and the Philippines. Sex Transm Dis. 2001; 28:187-194. [PubMed: 11318248]

27. Cherpes TL, Melan MA, Kant JA, Cosentino LA, Meyn LA, Hillier SL. Genital tract shedding of herpes simplex virus type 2 in women: effects of hormonal contraception, bacterial vaginosis, and 
vaginal group B Streptococcus colonization. Clin Infect Dis. 2005; 40:1422-1428. [PubMed: 15844064]

28. Ma G, Greenwell-Wild T, Lei K, Jin W, Swisher J, Hardegen N, Wild CT, Wahl SM. Secretory leukocyte protease inhibitor binds to annexin II, a cofactor for macrophage HIV-1 infection. J Exp Med. 2004; 200:1337-1346. [PubMed: 15545357]

29. Porter EM, van Dam E, Valore EV, Ganz T. Broad-spectrum antimicrobial activity of human intestinal defensin 5. Infect Immun. 1997; 65:2396-2401. [PubMed: 9169780]

30. Valore EV, Park CH, Quayle AJ, Wiles KR, McCray PB Jr, Ganz T. Human beta-defensin-1: an antimicrobial peptide of urogenital tissues. J Clin Invest. 1998; 101:1633-1642. [PubMed: 9541493]

31. Cole AM. Innate host defense of human vaginal and cervical mucosae. Curr Top Microbiol Immunol. 2006; 306:199-230. [PubMed: 16909923]

32. Hein M, Valore EV, Helmig RB, Uldbjerg N, Ganz T. Antimicrobial factors in the cervical mucus plug. Am J Obstet Gynecol. 2002; 187:137-144. [PubMed: 12114901]

33. Marchetti M, Trybala E, Superti F, Johansson M, Bergstrom T. Inhibition of herpes simplex virus infection by lactoferrin is dependent on interference with the virus binding to glycosaminoglycans. Virology. 2004; 318:405-413. [PubMed: 14972565]

34. Marchetti M, Ammendolia MG, Superti F. Glycosaminoglycans are not indispensable for the antiherpes simplex virus type 2 activity of lactoferrin. Biochimie. 2008

35. Jenssen H, Sandvik K, Andersen JH, Hancock RE, Gutteberg TJ. Inhibition of HSV cell-to-cell spread by lactoferrin and lactoferricin. Antiviral Res. 2008; 79:192-198. [PubMed: 18456345]

36. Devito C, Hinkula J, Kaul R, Kimani J, Kiama P, Lopalco L, Barass C, Piconi S, Trabattoni D, Bwayo JJ, Plummer F, Clerici M, Broliden K. Cross-clade HIV-1-specific neutralizing IgA in mucosal and systemic compartments of HIV-1-exposed, persistently seronegative subjects. J Acquir Immune Defic Syndr. 2002; 30:413-420. [PubMed: 12138348]

37. Belec L, Ghys PD, Hocini H, Nkengasong JN, Tranchot-Diallo J, Diallo MO, Ettiegne-Traore V, Maurice C, Becquart P, Matta M, Si-Mohamed A, Chomont N, Coulibaly IM, Wiktor SZ, Kazatchkine MD. Cervicovaginal secretory antibodies to human immunodeficiency virus type 1 (HIV-1) that block viral transcytosis through tight epithelial barriers in highly exposed HIV-1seronegative African women. J Infect Dis. 2001; 184:1412-1422. [PubMed: 11709783]

38. Hirbod T, Kaul R, Reichard C, Kimani J, Ngugi E, Bwayo JJ, Nagelkerke N, Hasselrot K, Li B, Moses S, MacDonald KS, Broliden K. HIV-neutralizing immunoglobulin A and HIV-specific proliferation are independently associated with reduced HIV acquisition in Kenyan sex workers. Aids. 2008; 22:727-735. [PubMed: 18356602]

39. Wilson CL, Schmidt AP, Pirila E, Valore EV, Ferri N, Sorsa T, Ganz T, Parks WC. Differential Processing of \{alpha $\}$ - and $\{$ beta $\}$-Defensin Precursors by Matrix Metalloproteinase-7 (MMP-7). J Biol Chem. 2009; 284:8301-8311. [PubMed: 19181662]

40. Shaw JL, Petraki C, Watson C, Bocking A, Diamandis EP. Role of tissue kallikrein-related peptidases in cervical mucus remodeling and host defense. Biol Chem. 2008; 389:1513-1522. [PubMed: 18844451]

41. Roumen FJ, Apter D, Mulders TM, Dieben TO. Efficacy, tolerability and acceptability of a novel contraceptive vaginal ring releasing etonogestrel and ethinyl oestradiol. Hum Reprod. 2001; 16:469-475. [PubMed: 11228213] 


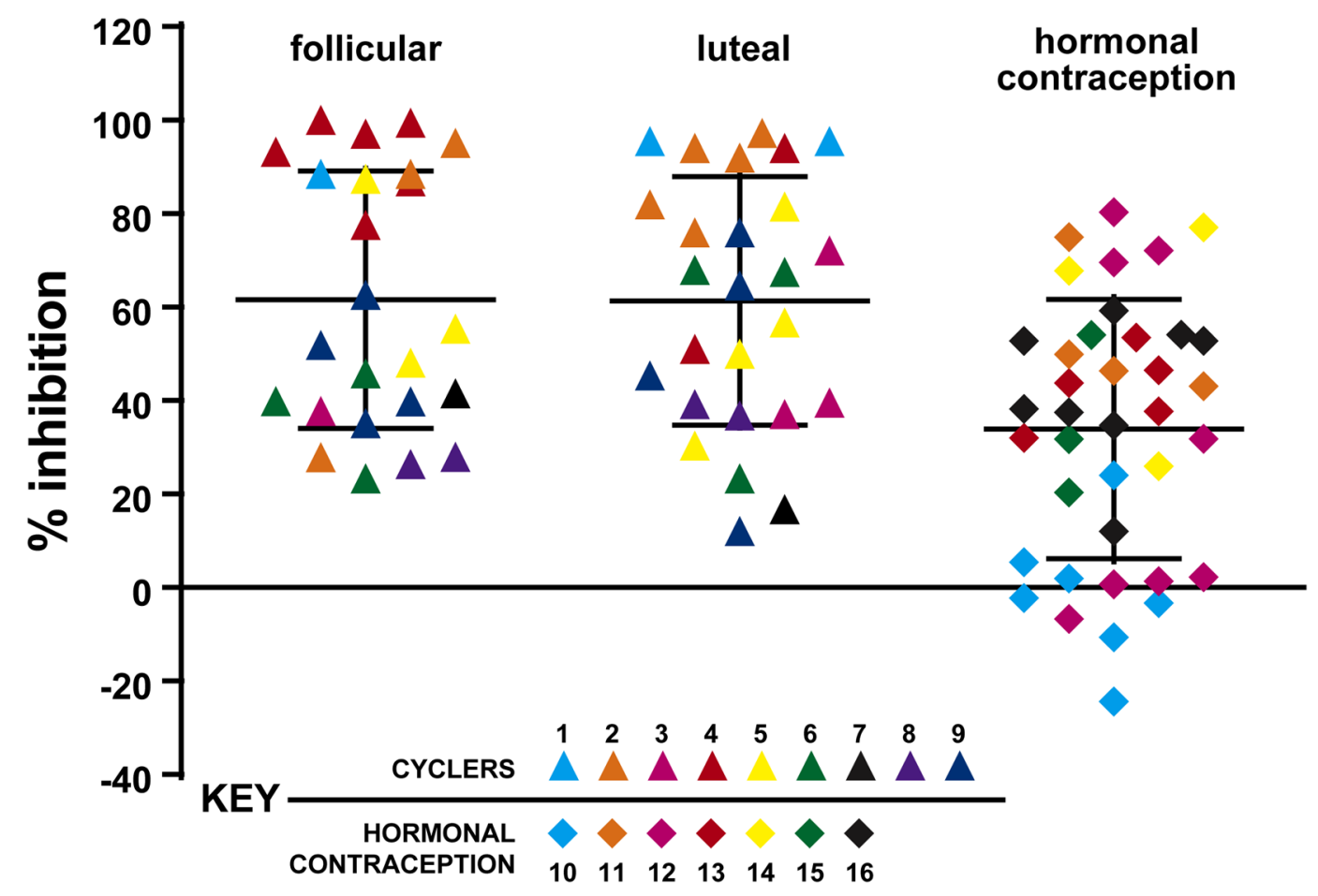

Fig. 1. Reduction in the endogenous anti-HSV activity in CVL obtained from women using hormonal contraception compared to cycling women in the follicular or luteal phase CaSki cells were infected with HSV-2(G) in the presence of each CVL sample or matched control buffer (PBS containing $200 \mu \mathrm{g} / \mathrm{ml} \mathrm{BSA}$, antibiotics and protease inhibitors) and viral plaques counted 48 hours post-infection. Each point represents the percentage reduction in viral plaque formation relative to cells treated with control buffer obtained from two independent experiments conducted in duplicate. Each color represents a different participant. The bars indicate means \pm SD for the group. 

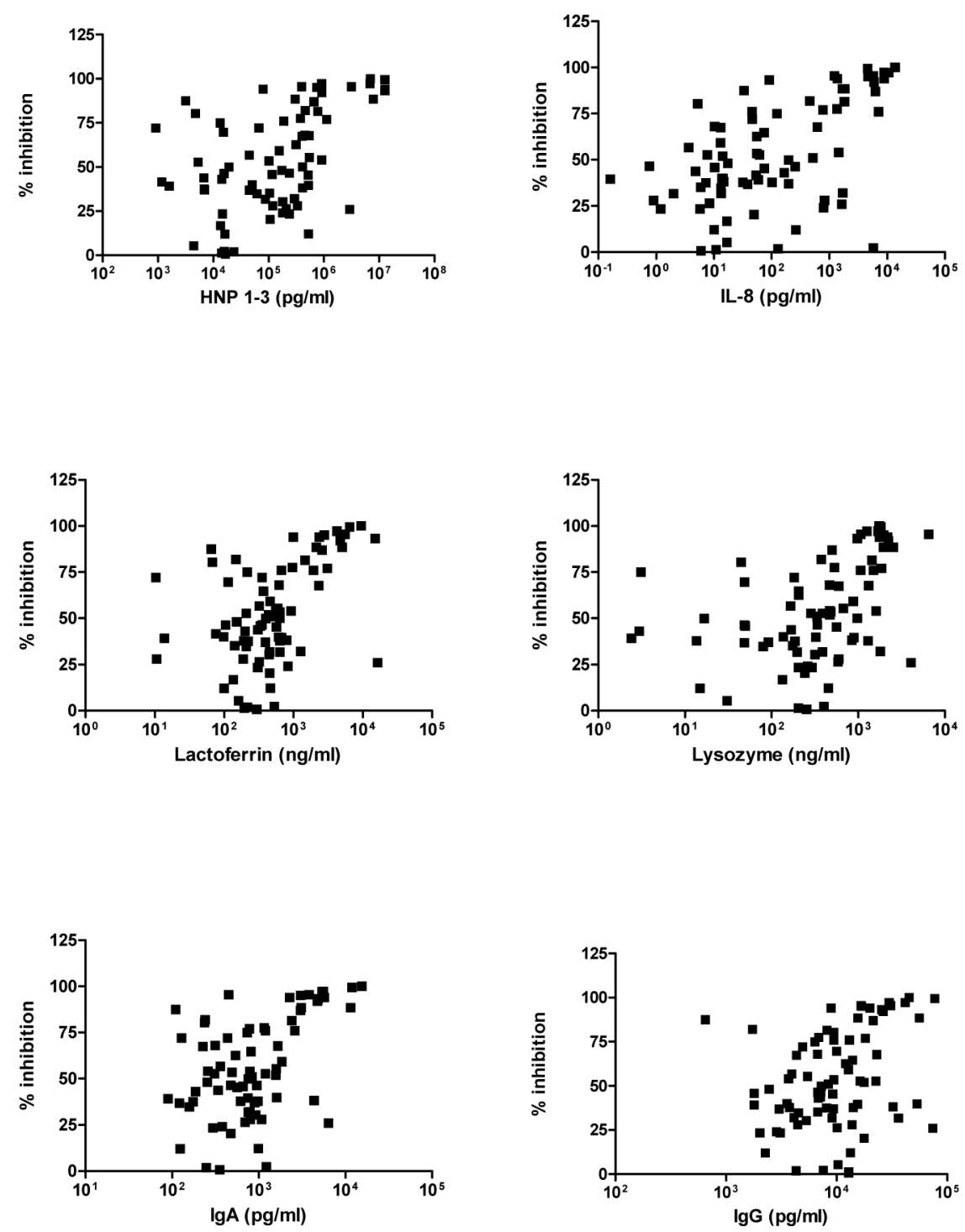

Fig. 2. Anti-HSV activity correlates with soluble mucosal immune mediators

The concentrations of HNP1-3, IL-8, lactoferrin, lysozyme, IgA, and IgG were determined and the data log transformed. The percentage inhibition of HSV infection was determined by plaque assay. Each symbol represents the results obtained from a single CVL sample tested in duplicate in two independent experiments. Correlation coefficients were determined by weighted Pearson product-moment correlations (See Table 2) 


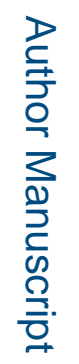

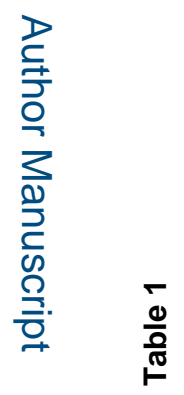

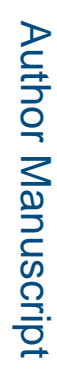
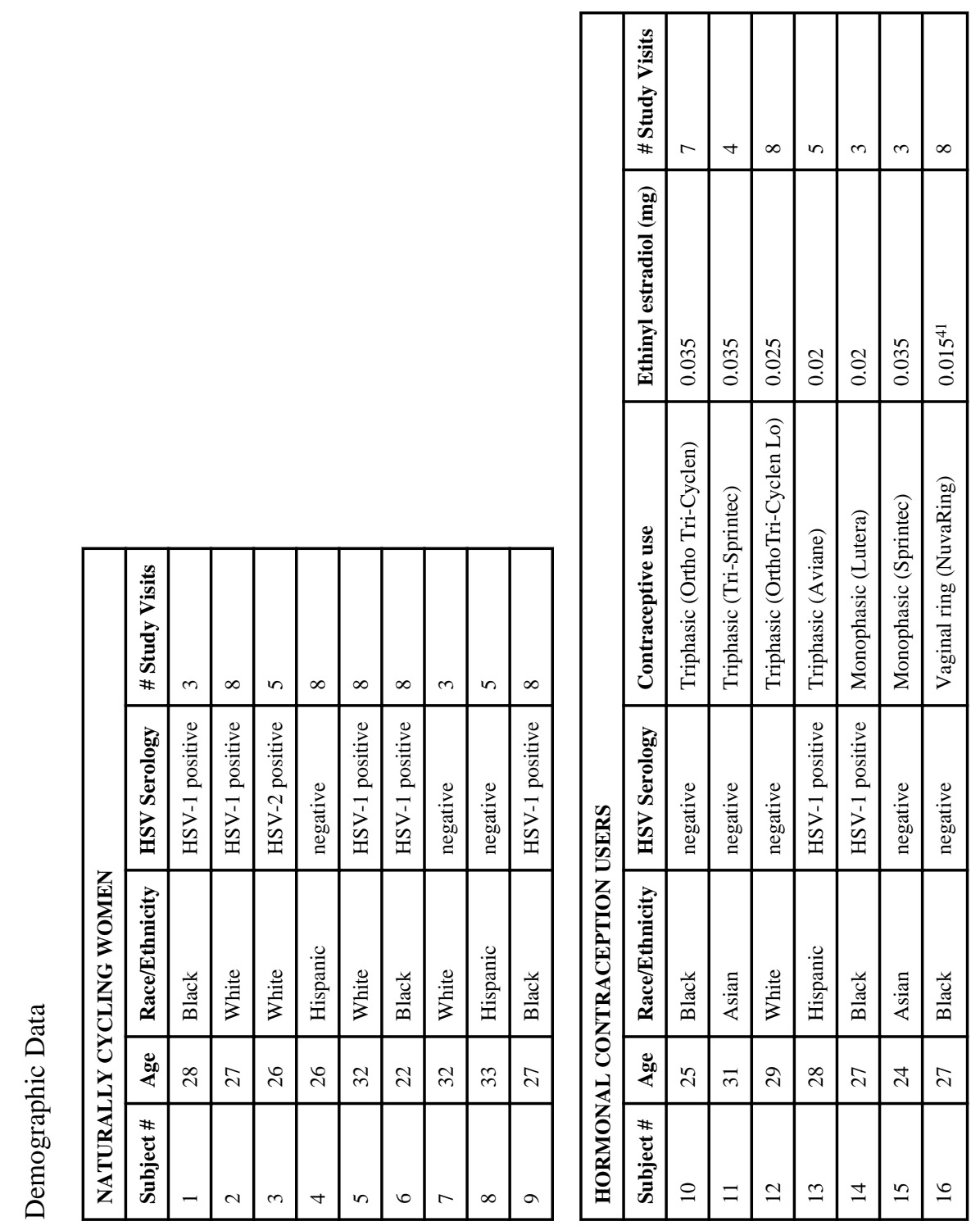

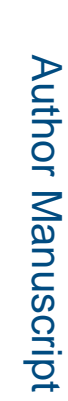

Am J Reprod Immunol. Author manuscript; available in PMC 2015 May 04. 


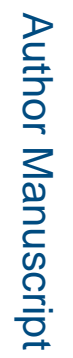

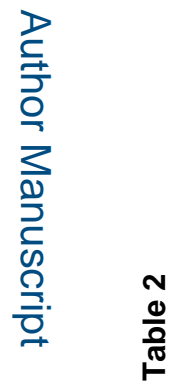

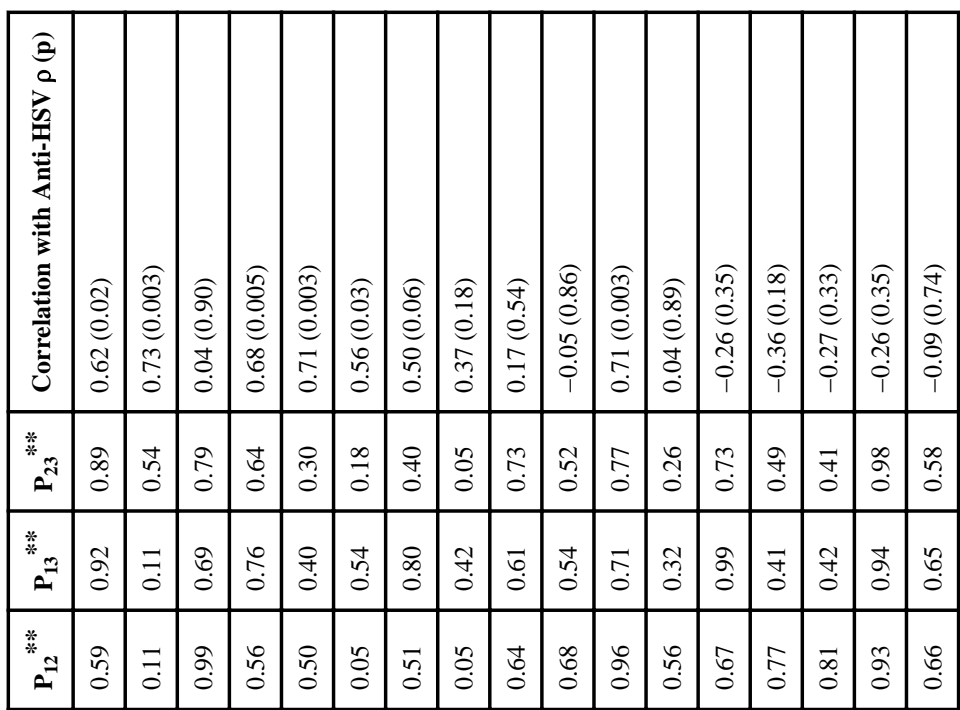

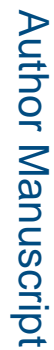

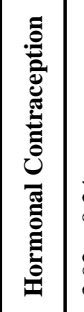

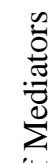

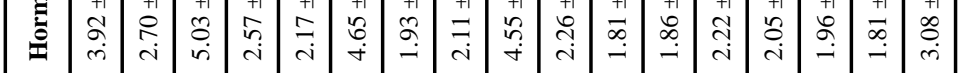

『ే

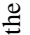

章

零

$\stackrel{9}{ \pm}$

突

离

$\stackrel{\frac{0}{0}}{\frac{2}{0}}$

.

远

范

웅

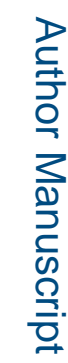

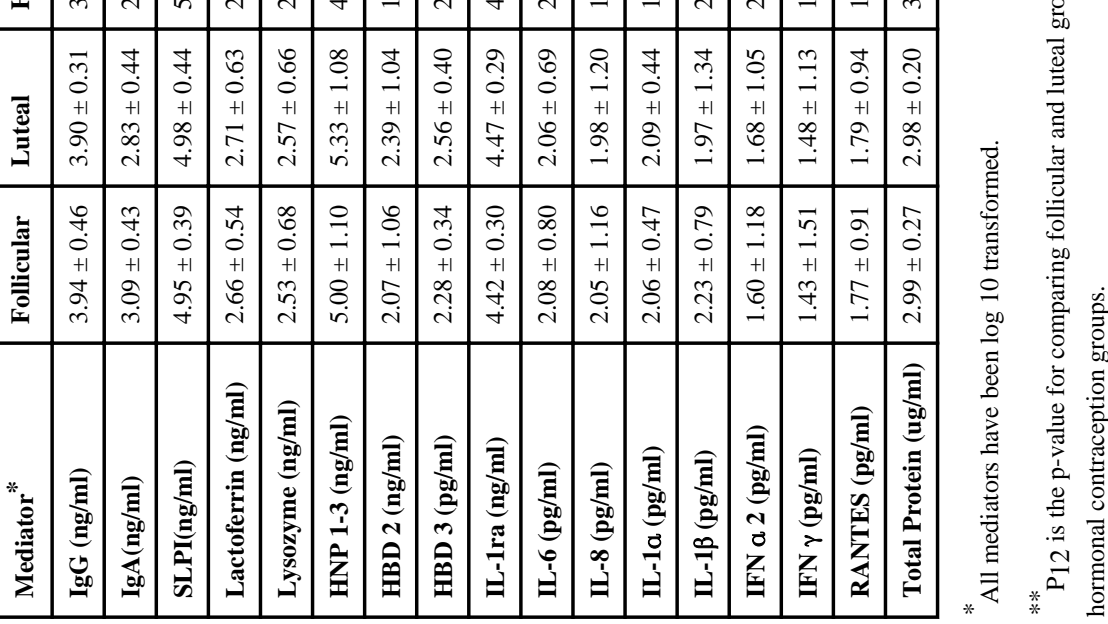

Am J Reprod Immunol. Author manuscript; available in PMC 2015 May 04. 


\section{Table 3}

Intra-class correlation coefficients (ICC) of antiviral activity and concentration of immune mediators.

\begin{tabular}{|l|l|l|l|}
\hline Mediator & Follicular & Luteal & Hormonal Contraception \\
\hline Anti-HSV & 0.63 & 0.44 & 0.44 \\
\hline IgG (ng/ml) & 0.65 & 0.51 & 0.36 \\
\hline IgA(ng/ml) & 0.58 & 0.61 & 0.27 \\
\hline SLPI(ng/ml) & 0.49 & 0.38 & 0.20 \\
\hline Lactoferrin (ng/ml) & 0.41 & 0.73 & 0.65 \\
\hline Lysozyme (ng/ml) & 0.84 & 0.58 & 0.74 \\
\hline HNP 1-3 (ng/ml) & 0.44 & 0.79 & 0.65 \\
\hline HBD 2 (ng/ml) & 0.37 & 0.85 & 0.68 \\
\hline HBD 3 (pg/ml) & 0.37 & 0.06 & 0.19 \\
\hline IL-1ra (ng/ml) & 0.51 & 0.41 & 0.66 \\
\hline IL-6 (pg/ml) & 0.27 & 0.59 & 0.63 \\
\hline IL-8 (pg/ml) & 0.82 & 0.71 & 0.86 \\
\hline IL-1a (pg/ml) & 0.23 & 0.57 & 0.27 \\
\hline IL-1 $\beta$ (pg/ml) & 0.53 & 0.70 & 0.92 \\
\hline IFN a 2 (pg/ml) & 0.64 & 0.81 & 0.81 \\
\hline IFN $\gamma(\mathbf{p g} / \mathbf{m l )}$ & 0.82 & 0.80 & 0.79 \\
\hline RANTES (pg/ml) & 0.80 & 0.89 & 0.89 \\
\hline Total Protein (ug/ml) & 0.69 & 0.76 & 0.57 \\
\hline & & & \\
\hline
\end{tabular}

